\title{
OS ESTUÁRIOS DO NORDESTE DO BRASIL E O DESENVOLVIMENTO SUSTENTÁVEL: USOS MÚLTIPLOS E IMPACTOS. O ESTUÁRIO DO RIO TIMBÓ COMO UM ESTUDO DE CASO.
}

\author{
Adilson Luiz CABRAL ${ }^{1}$, \\ Roberto SASSI ${ }^{2 *}$ \\ Cristiane \\ COSTA $^{3}$
}

\begin{abstract}
${ }^{1}$ Universidade de Pernambuco. Departamento do Instituto de Ciências Biológicas. Rua Arnóbio Marques, 310, Santo Amaro, 50.100-130 - Recife, Pernambuco, Brasil.

${ }^{2}$ Universidade Federal da Paraíba/Departamento de Sistemática e Ecologia/CCEN/NEPREMAR/PRODEMA (Cidade Universitária - Campus I, 58059-900 João Pessoa, Paraíba, Brasil) *E-mail: rsassi@nepremar.ufpb.br

${ }^{3}$ Universidade Federal da Paraíba/NEPREMAR/Programa de Pós-Graduação em Ciências Biológicas/Zoologia (Doutorado), Cidade Universitária - Campus I, 58059-900 João Pessoa, Paraíba, Brasil
\end{abstract}

Recebido: $19 / 09 / 05$

Aceito: 30/09/05

\section{RESUMO}

Fortes competições entre o poder econômico e os usos tradicionais dos recursos e do espaço estuarino no Nordeste do Brasil normalmente promovem grandes impactos e resultam em contrastes sociais e conflitos. Neste trabalho nós inventariamos os diferentes tipos de impactos antropogênicos no estuário do rio Timbó, Estado de Pernambuco, usando um modelo de "checklist” para áreas estuarinas. Foram encontradas grandes diferenças entre as duas margens do estuário quanto aos impactos inventariados. Modificações na paisagem (perdas estéticas) invasões, coletas de moluscos e crustáceos, cortes da vegetação de mangue, navegação, plantações extensivas de coco nas proximidades do estuário, agricultura, e trapiches foram os mais importantes. As melhores localidades (índices de qualidade ambiental superiores a 0,70) foram encontradas somente em comunidades tradicionais. A priorização por Pareto mostrou 15 tipos de interferências respondendo por $80 \%$ dos problemas na área. Implicações ecológicas e sociais desses usos conflitantes e impactos são discutidas e medidas de remediação sugeridas.

Palavras chaves: Manejo estuarino, conflitos de uso, comunidades tradicionais, relação sociedadenatureza, Nordeste do Brasil.

\section{ABSTRACT \\ ESTUARINE USES AND IMPACTS IN NORTHEASTERN BRASIL AND THE CONTEXT OF SUSTAINABLE DEVELOPMENT. THE RIVER TIMBÓ ESTUARY AS A CASE STUDY, STATE OF PERNAMBUCO.}

Strong competitions between the economic power and the traditional uses of estuarine resources and spaces in the Northeast of Brazil usually promote greater impacts and results in social contrasts and conflicts. In this paper we inventoried the different kinds of anthropogenic impacts in the River Timbó estuary, State of Pernambuco, using a check-list model for estuarine areas. Greater differences were found between the western and eastern margins regarding the environmental impacts. Landscape changes (aesthetic losses), invasions, catches of mussels and crabs, mangrove 
woodcutting, shipping, coconut extensive near the estuary, agriculture, and piers were the most important. The best sites (environmental quality index up to 0.70 ) were found only in traditional communities of artisan fishermen. Pareto's priorization showed 15 kinds of interference responding for $80 \%$ of the problems in the area. Ecological and social implications of these conflicting uses and impacts are discussed and remedial measures are suggested.

Key words: Estuarine management, conflicting uses, traditional communities, society-nature relations, Northeastern Brazil.

\section{INTRODUÇÃO}

Os estuários e os manguezais associados oferecem um leque muito amplo de serviços ecológicos e sociais, que incluem desde a alimentação das fases jovens de animais estuarinodependentes e fertilização costeira através da exportação de nutrientes e detritos, até a produção de alimento, recreação, turismo, pesquisa científica, comércio e remoção de nutrientes oriundos das atividades humanas, entre outros (HAMILTON; SNEDAKER, 1984; DAME; ALLEN, 1996; VIDAL; SASSI, 2000). A importância desses ecossistemas perpassa, portanto, a dimensão ecológica, transpondo-se para o econômico e o social.

Entretanto, o excessivo contingente populacional que existe hoje na zona costeira tem fragilizado fortemente essas áreas (FRENCH, 1997; CICIN-SAIN; KNECHT, 1998). Nos estuários, as interferências humanas incluem desde a exploração de alimento, extração de materiais de construção, transporte, recreação e deposição de esgotos (AWOSISKA; MARONE, 2000) até obras de engenharia e atividades agrícolas desenvolvidas ao longo das suas bacias de drenagem. Invasões de áreas públicas e aterros de áreas de mangue para propósitos múltiplos representam uma prática comum nessas áreas (MARCELINO, 2000) e as atividades de aqüicultura (HUITRIC et al., 2002) e pesca predatória são exemplos adicionais dessas tensões.

Com freqüência, a ação humana nos ambientes costeiros tem provocado contaminação de águas estuarinas, assoreamento e eutrofização, com conseqüências biológicas e sociais muito grandes (KUSUMA-ATMADJA; PURWAKA 1996; FLINDT et al., 1999). Também têm provocado modificações no desenvolvimento dos manguezais e na biodiversidade, muitas vezes levando à eliminação de espécies sensíveis (CINTRÓN; SCHAEFFER-NOVELLI, 1984; KUSUMA-ATMADJA; PURWAKA, 1996). Muitos estuários também abrigam portos e empresas de navegação e suas áreas experimentam forte desenvolvimento urbano. Essas atividades crescem exponencialmente em muitos locais e frequentemente são conflitantes.

A região nordeste do Brasil abriga uma grande quantidade de estuários e ainda contém uma considerável área de manguezais bem estruturados. Mas infelizmente também é uma região aonde os ambientes de mangue vem sofrendo grandes impactos (ALVES; SASSI, 2003). Além da poluição muitos manguezais vêm sendo suprimidos para a prática da carcinicultura e aterros dessas áreas para a expansão urbana são freqüentes, particularmente nas proximidades das grandes cidades.

Em Pernambuco, por exemplo, esses ambientes têm sido tradicionalmente muito impactados. Em Recife, capital do Estado, existe mais de 600 áreas de assentamentos invadidos onde vivem mais da metade da população do município (MOURA, 1990; ASSIES, 1992; SOUZA, 1999), a maioria em áreas de mangue. O contraste entre os serviços ecológicos e sociais fornecidos gratuitamente pelos estuários e manguezais existentes neste Estado, e os usos múltiplos desses ecossistemas, demonstra que é premente a avaliação dos impactos ambientais decorrentes das atividades humanas desenvolvidas nessas áreas. A carência de dados a este respeito contrasta com o acumulo de informações obtidas sobre aspectos físicos, químicos, geológicos e biológicos, tradicionalmente muito estudados (por exemplo: MELLO, 1979; PASSAVANTE, 1979; ESKINAZI-LEÇA et al., 1980; CAVALCANTI et al., 1981; PARANAGUÁ; NEUMANNLEITÃO, 1980; VASCONCELOS FILHO; RAMOS-PORTO, 1987, BRAGA et al., 1989; SÔNIADA-SILVA ET AL., 2000; FONSÊCA et al., 2000; SCHWAMBORN ET AL., 2001; EKAU et al.,

Tropical Oceanography, Recife, v. 33, n. 2, p. 199-206, 2005. 
2001; MOURA; COELHO, 2003; HONORATO DA SILVA et al., 2004; BASTOS et al., 2005; etc.) e indica que esta lacuna necessita ser preenchida urgentemente. Alguns estudos sobre impactos humanos em ambientes de mangue foram desenvolvidos por Silva (1990), em Vila Velha, Ilha de Itamaracá; Silva (1995), no rio Paripe; Silva (2001), no Canal de Santa Cruz, Itapissuma; mas esses trabalhos enfocaram principalmente aspectos estruturais do bosque. Souza; Neumann-Leitão (2000) também efetuaram uma avaliação das conseqüências sócio-econômicas dos impactos antrópicos no estuário do rio São Francisco, em Brejo Grande, Estado de Sergipe, enfatizando principalmente a pesca.

O presente estudo teve como principal propósito caracterizar os impactos antrópicos no espaço estuarino do rio Timbó, Pernambuco, Nordeste do Brasil. A idéia central é que as formas atuais de uso da área e de manejo dos recursos e dos espaços estuarinos da região geram grandes modificações ambientais que não se enquadram no modelo de desenvolvimento sustentável preconizado no Princípio $3^{\circ}$ da Declaração do Rio sobre Meio Ambiente e Desenvolvimento (AGENDA 21). Necessitam, portanto, serem avaliadas, a fim de gerar subsídios que possam assegurar no futuro programas de manejo que garantam a sustentabilidade ambiental.

\section{MATERIAL E MÉTODOS}

As interferências humanas que ocorrem na área de influência direta da região estuarina do rio Timbó, Estado de Pernambuco, foram avaliadas conforme procedimentos descritos em Rhode (1988) e Tommasi (1994) mediante a elaboração de uma matriz escalar ponderada que relaciona os principais impactos evidenciados na área. A pesquisa foi realizada ao longo do ano 2000, em 17 setores marginais do estuário, dos quais 9 situam-se na margem direita e 8 na margem esquerda (Figura 1).

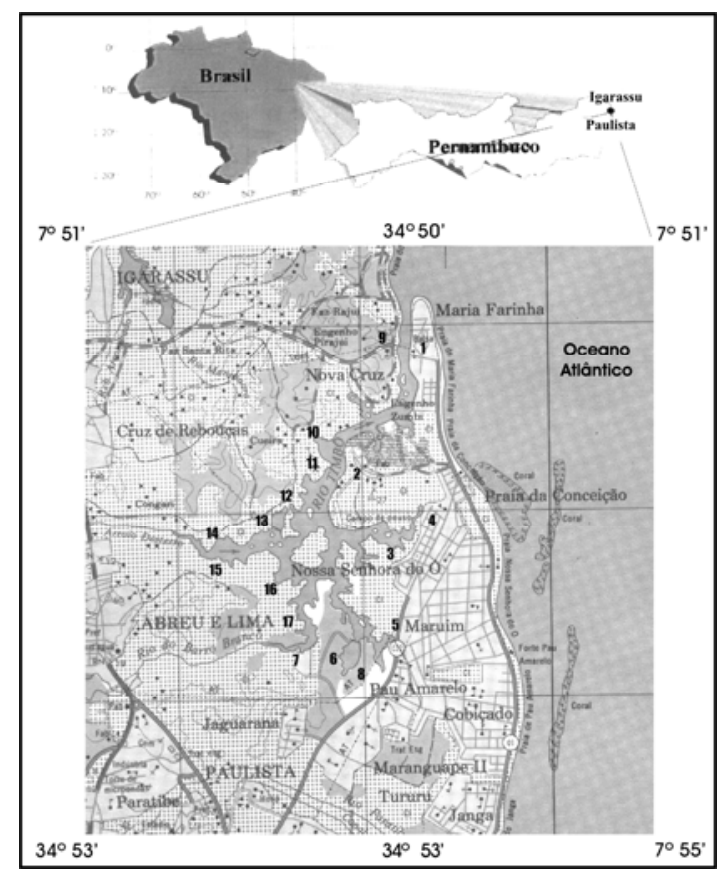

Figura 1 - Mapa do estuário do rio Timbó, Estado de Pernambuco, e localização dos setores (1 a 17) demarcados para estudo. 
Foi utilizado um GPS 48 (Global Position System) portátil, de marca Garmin, para se estabelecer a posição de cada localidade nas margens do referido estuário (Tabela 1). As magnitudes de todos os impactos inventariados foram hierarquizados e priorizados de acordo com a regra 80:20 de Pareto (ALVES et al., 2004). Um índice de qualidade ambiental (MARCELINO, 2000) variando de 0 (péssima qualidade) a 1 (qualidade excelente) foi calculado para cada setor considerado, tomando-se como base a seguinte equação: IQA $=\sum$ pic $-\sum$ pri $/ \sum$ pic, onde pic = peso máximo $(=3)$ de cada impacto considerado e pri $=$ peso real atribuído aos impactos observados.

Tabela 1 - Posição geográfica aproximada das localidades pesquisadas nas margens do estuário do rio Timbó, Estado de Pernambuco.

\begin{tabular}{|c|c|c|c|c|}
\hline Margem & Setores & Localidades & Lat. (S) & Long. (W) \\
\hline Direita & 1 & Maria Farinha & $07^{0} 51^{\prime} 12,4^{\prime \prime}$ & $34^{\circ} 50^{\prime} 26,5^{\prime \prime}$ \\
\hline Direita & 2 & Fábrica Poty & $07^{\circ} 53^{\prime} 28,0^{\prime \prime}$ & $34^{\circ} 50^{\prime} 42,7^{\prime \prime}$ \\
\hline Direita & 3 & Favela GG & $07^{\circ} 53^{\prime} 53,2$ “ & $34^{\circ} 50^{\prime} 32,7^{\prime \prime}$ \\
\hline Direita & 4 & Favela Tururu (Lot. Pr. da Conceição) & $07^{\circ} 54^{\prime} 50,4^{\prime \prime}$ & $34^{\circ} 50^{\prime} 24,8^{\prime \prime}$ \\
\hline Direita & 5 & Favela Chega Mais (Lot. Pr. da Conceição) & $07^{\circ} 54^{\prime} 31,0^{\prime \prime}$ & $34^{\circ} 50^{\prime} 38,4^{\prime \prime}$ \\
\hline Direita & 6 & Jaguarana & $07^{\circ} 50^{\prime} 13,3^{\prime \prime}$ & $34^{\circ} 51^{\prime} 01,1^{\prime \prime}$ \\
\hline Direita & 7 & Urubá & $07^{\circ} 54^{\prime} 40,8$ “ & $34^{\circ} 51^{\prime} 53,1^{\prime \prime}$ \\
\hline Direita & 8 & Porto do Arthur & $07^{\circ} 54^{\prime} 24,6^{\prime \prime}$ & $34^{\circ} 51^{\prime} 40,7^{\prime \prime}$ \\
\hline Esquerda & 9 & Nova Cruz & $07^{\circ} 51^{\prime} 08,0^{\prime \prime}$ & $34^{\circ} 50^{\prime} 35,8^{\prime \prime}$ \\
\hline Esquerda & 10 & Cuieiras & $07^{\circ} 52^{\prime} 23,1^{\prime \prime}$ & $34^{\circ} 52^{\prime} 16,4^{\prime \prime}$ \\
\hline Esquerda & 11 & Fazenda Gongaçari & $07^{\circ} 53^{\prime} 15,8^{\prime \prime}$ & $34^{\circ} 52^{\prime} 39,0^{\prime \prime}$ \\
\hline Esquerda & 12 & Sítio Iamã & $07^{\circ} 53^{\prime} 32,7^{\prime \prime}$ & $34^{\circ} 53^{\prime} 41,6^{\prime \prime}$ \\
\hline Esquerda & 13 & Porto Jatobá & $07^{\circ} 53^{\prime} 36,1^{\prime \prime}$ & $34^{\circ} 52^{\prime} 51,0^{\prime \prime}$ \\
\hline Esquerda & 14 & Porto de Baixo & $07^{\circ} 53^{\prime} 34,2^{\prime \prime}$ & $34^{\circ} 52^{\prime} 19,9^{\prime \prime}$ \\
\hline Esquerda & 15 & Fosfato & $07^{\circ} 53^{\prime} 28,5^{\prime \prime}$ & $34^{\circ} 52^{\prime} 23,4^{\prime \prime}$ \\
\hline Esquerda & 16 & Sítio São Bento & $07^{\circ} 54^{\prime} 02,6^{\prime \prime}$ & $34^{\circ} 53^{\prime} 18,9^{\prime \prime}$ \\
\hline Esquerda & 17 & Jaguaribe & $07^{\circ} 55^{\prime} 09,9 "$ & $34^{\circ} 53^{\prime} 29,3^{\prime \prime}$ \\
\hline
\end{tabular}

\section{RESULTADOS}

Diferenças espaciais foram constatadas quanto aos tipos e intensidade de impactos. Nas proximidades da desembocadura, particularmente em Maria Farinha (margem direita) e Nova Cruz (margem esquerda), foram mais evidentes tensões antrópicas provocadas por obras de engenharia voltadas para atendimento ao turismo e atividades recreacionais (atracadouros, marinas, hotéis, etc.), navegação e invasão de áreas públicas para instalação de equipamentos industriais, como a fabrica de Cimento Poty, localizada na margem direita. Nas porções mais internas as principais interferências associaram-se mais com a necessidade de sobrevivência das comunidades ribeirinhas, onde a pesca, coleta de moluscos, suinocultura, etc., foram as atividades antrópicas mais comuns, observadas em Maria Farinha, Favela GG, Favela Tururu e Favela Chega Mais (margem direita) e Nova Cruz (margem esquerda). A margem direita do estuário mostrou-se mais comprometida integralizando 216 pontos contra 139 na margem esquerda segundo os critérios de avaliação dos impactos considerados (Tabela 2). 
Tabela 2 - Principais impactos antrópicos evidenciados na área estuarina do rio Timbó, Estado de Pernambuco inventariados no ano de $2000(\bullet=$ impactos críticos (valor 3); $\bigcirc$ = moderados (valor 2 ); $\bigcirc$ = de pequena expressividade (valor 1 )).

\begin{tabular}{|c|c|c|c|c|c|c|c|c|c|c|c|c|c|c|c|c|c|}
\hline TIPOS DE IMPACTOS & 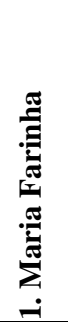 & 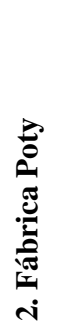 & 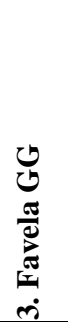 & 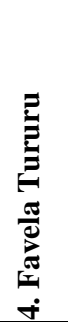 & 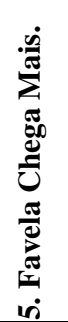 & 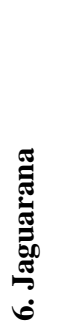 & 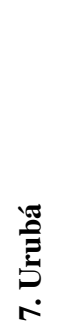 & 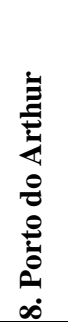 & 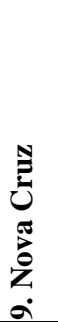 & 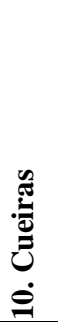 & 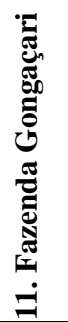 & 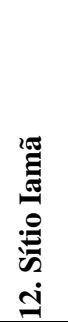 & 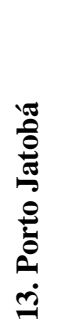 & 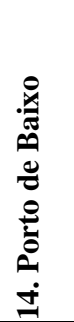 & 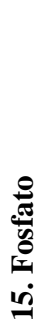 & 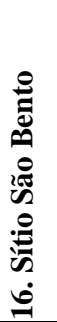 & 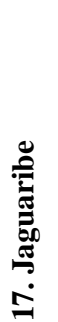 \\
\hline & \multicolumn{8}{|c|}{ Margem direita } & \multicolumn{9}{|c|}{ Margem esquerda } \\
\hline 1. Alterações da paisagem & - & 0 & - & 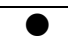 & $\bullet$ & $\mathrm{O}$ & 0 & $\mathrm{O}$ & - & $\mathrm{O}$ & $\mathrm{O}$ & O & $\mathrm{O}$ & $\mathrm{O}$ & & 0 & 0 \\
\hline 2. Agricultura extensiva de coco & ○ & 0 & & & & & & - & - & ○ & 0 & 0 & & & & ○ & 0 \\
\hline 3. Agricultura de subsistência & $\bigcirc$ & & & & & $\odot$ & 0 & & ○ & ○ & $\bigcirc$ & 0 & & & & 0 & 0 \\
\hline 4. Suinocultura & & & 0 & ○ & 0 & & & & & & & & & & & & \\
\hline 5. Atividades comerciais & & & 0 & 0 & 0 & 0 & 0 & & ○ & 0 & & 0 & & & & 0 & 0 \\
\hline 6. Atividades recreacionais e turísticas & - & & & & & $\bigcirc$ & & ○ & $\odot$ & $\bigcirc$ & 0 & & 0 & 0 & & 0 & 0 \\
\hline 7. Viveiros & & & & & & ○ & & & $\bigcirc$ & & $\odot$ & & & & & & \\
\hline 8. Pesca artesanal & $\odot$ & $\odot$ & ○ & $\odot$ & $\odot$ & ○ & $\odot$ & 0 & $\odot$ & $\odot$ & $\bigcirc$ & $\odot$ & $\odot$ & $\odot$ & ○ & $\odot$ & $\odot$ \\
\hline 9. Pesca esportiva & $\bigcirc$ & $\bigcirc$ & & & & & & $\bigcirc$ & $\bigcirc$ & $\bigcirc$ & & & & & & & \\
\hline 10. Coleta de moluscos e crustáceos & $\odot$ & ○ & ○ & ○ & ○ & ○ & $\odot$ & $\bigcirc$ & $\odot$ & ○ & 0 & ○ & 0 & 0 & ○ & 0 & 0 \\
\hline 11. Captura e abate de aves & 0 & & & & & 0 & 0 & & 0 & & & & & & & & \\
\hline 12. Extração de remédios do manguezal & $\bigcirc$ & 0 & 0 & 0 & 0 & $\bigcirc$ & $\bigcirc$ & & $\bigcirc$ & 0 & 0 & 0 & 0 & 0 & 0 & 0 & 0 \\
\hline 13. Queimadas no manguezal & 0 & 0 & - & ○ & ○ & ○ & & 0 & 0 & & & & & & & & \\
\hline 14. Cortes na vegetação de mangue & O & ○ & - & - & - & 0 & & 0 & 0 & 0 & & & 0 & & & & \\
\hline 15. Invasão de áreas públicas & - & ○ & - & - & - & 0 & 0 & & - & 0 & & & & & & & \\
\hline 16. Favelas & $\odot$ & & - & - & - & & & & & & & & & & & & \\
\hline 17. Linhas de transmissão & 0 & 0 & 0 & & & & & & 0 & & & & & & & & \\
\hline 18. Especulação imobiliária & - & & & & & & & & - & & & & & & & & \\
\hline
\end{tabular}


Tabela 2 - Principais impactos antrópicos evidenciados na área estuarina do rio Timbó, Estado de Pernambuco inventariados no ano de 2000 críticos (valor 3); $\bigcirc$ = moderados (valor 2); $\bigcirc=$ de pequena expressividade (valor 1 )). Continuação

19. Atracadouros e rampas

20. Navegação

22. Entulho de construções

23. Esgoto doméstico clandestino

24. Esgoto municipal (COMPESA)

25. Esgotos industriais

26. Deposição de Lixo

27. Processos erosivos

28. Assoreamento

Totais de pontos nas localidades

Total de pontos por margem

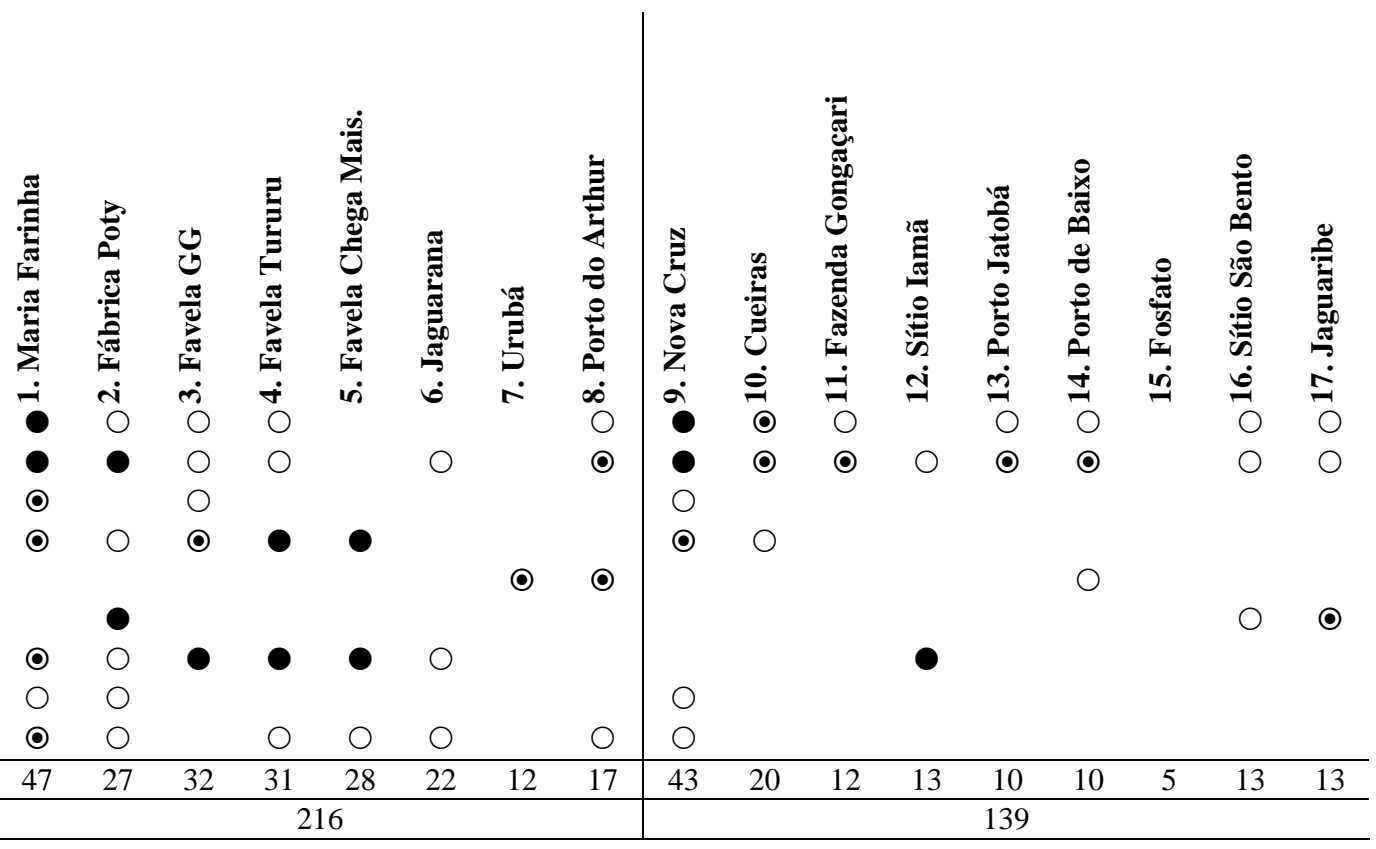

Tropical Oceanography, Recife, v. 33, n. 2, p. 199-206, 2005. 
O diagrama de Pareto mostrou que existem 15 tipos de interferências humanas que respondem por $80 \%$ dos problemas na área (Fig. 2). As atividades que mais se destacaram na análise hierárquica dos impactos e que foram encontradas em praticamente todos os setores investigados foram aquelas relacionadas com a pesca e coleta de moluscos e crustáceos, alterações na paisagem, navegação, invasões de área públicas e lixo. Queimadas no manguezal, presença de linhas de transmissão, agricultura extensiva de coco, extração de remédios naturais oriundos de produtos do manguezal e deposição de esgoto doméstico, tiveram maiores pontuações apenas em algumas das localidades estudadas (Tabela 2).

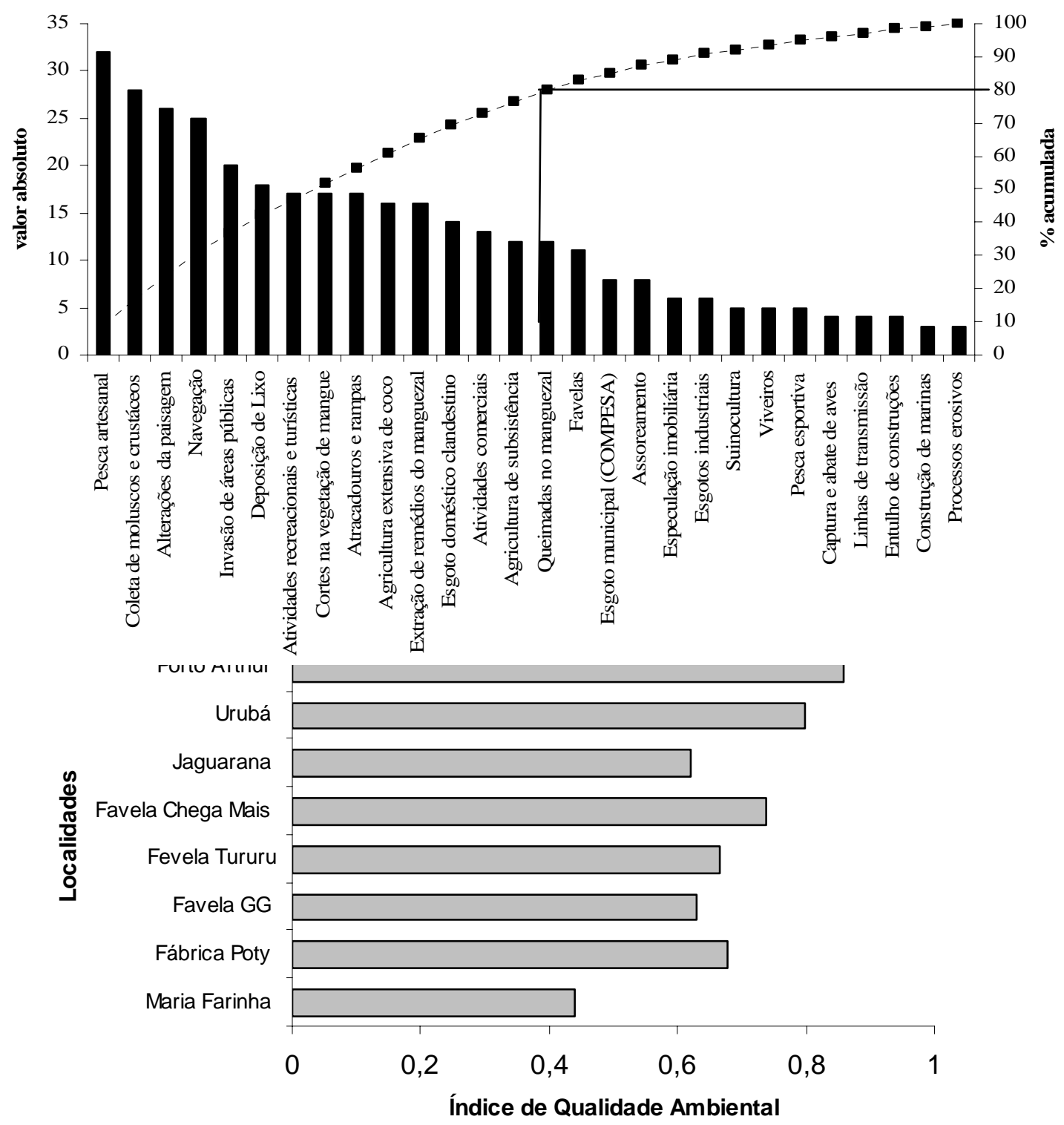

Figura 3 - Índice de Qualidade Ambiental das áreas estuarinas do rio Timbó, na margem direita.

Tropical Oceanography, Recife, v. 33, n. 2, p. 199-206, 2005. 


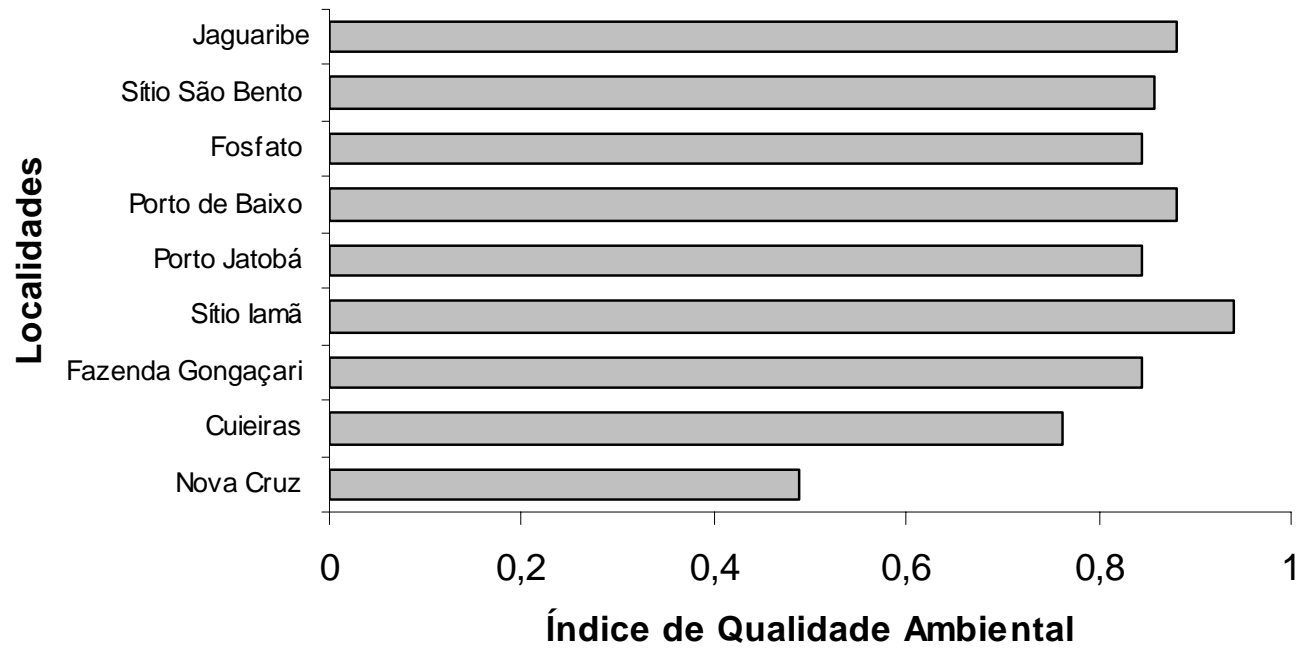

Figura 4 - Índice de Qualidade Ambiental das áreas estuarinas do rio Timbó, margem esquerda.

\section{DISCUSSÃO}

As diferentes formas de uso e ocupação do espaço estuarino do rio Timbó, conforme foi evidenciado nesta pesquisa, demonstram que a área é extremamente vulnerável frente às tensões antrópicas. Em alguns setores estas tensões têm-se amplificado resultando em perda de qualidade ambiental e, em conseqüência, de valores ecológicos, econômicos, estéticos, recreacionais e turísticos, com reflexos no bem estar da população.

As interferências humanas que mais se destacaram, de acordo com os critérios de pontuação adotados, estão associadas com as atividades desenvolvidas tanto por residentes estuarinos como por pessoas de fora que mantém algum tipo de ganho no local, ou que procuram o estuário para sobrevivência. Portanto, são conseqüências do processo histórico de ocupação da área e podem ser relacionadas com o modo de vida das populações que se interagem com os diferentes setores do estuário.

As atividades que envolvem diretamente as formas vigentes de economia capitalista cumulativa predominam claramente nas proximidades da desembocadura, contrastando com as porções mais internas onde as atividades associam-se mais com a necessidade de sobrevivência das comunidades ribeirinhas. No primeiro caso, destacam-se as construções voltadas para atendimento ao turismo e recreação, navegação e instalação de equipamentos industriais; no segundo, as principais tensões associam-se com as pressões laterais decorrentes da expansão urbana e processos de favelização em áreas públicas invadidas, deposição de esgoto doméstico, lixo e entulho, atividades extrativistas como a pesca, catação de moluscos e crustáceos, retirada de madeira do mangue e em menor escala a procura por medicamentos naturais.

Algumas das interferências observadas são modestas e, portanto, tem pequena expressividade, como o uso de plantas medicinais, uma prática comum na região, que também é comum em outras partes do mundo (PREMANATHAN et al., 1999); mas outras, claramente trazem sérias implicações ao ecossistema, a exemplo dos esgotos domésticos e do lixo, que além de provocarem alterações na paisagem, criam odores e introduzem substâncias tóxicas no ambiente, que em última escala trazem riscos para a saúde pública.

Tropical Oceanography, Recife, v. 33, n. 2, p. 199-206, 2005. 
Os esgotos lançados pelas comunidades marginais e pela COMPESA (Companhia Pernambucana de Saneamento Ambiental) distribuem-se ao longo do estuário pela ação das marés, trazendo sérias implicações ecológicas e alterações estéticas no ambiente. Sua presença também é incompatível tanto com o turismo e recreação como com as atividades produtivas como a pesca e a aqüicultura. A presença dos esgotos domésticos em estuários aumenta a respiração total do sistema (LUGO et. al., 1980) e leva à eutrofização. O rio Timbó parece caminhar para este quadro, pois já possui áreas com elevada DBO, anoxia, transparência da água reduzida, alterações do $\mathrm{pH}$ e altas concentrações de coliformes fecais, demonstrando, assim, características típicas de ambientes eutróficos (CPRH, 1997, 1999). Este processo resulta em perdas de habitats valiosos e alterações nos estoques pesqueiros (FLINDT et al. 1999; VALIELA; BOWEN, 2002), além de causar sérios problemas para usos recreacionais e para a saúde pública devido à proliferação de microalgas e organismos patogênicos (BRAGA et al., 2000).

As favelas representam as formas mais degradantes de ocupação do espaço e constituem prática comum em outros estuários do nordeste (MARCELINO, 2000). Contrastam fortemente com muitas atividades associadas à acumulação de bens, como o turismo e a recreação (SASSI et al., 2005).

A extração de madeira de mangue também é prática comum em outros estuários do Brasil (MARCELINO, 2000). Provavelmente, o caso mais espantoso foi registrado na laguna de Intermares, estado da Paraíba, ao norte de Pernambuco, aonde os índices de cortes chegaram a 1576 cortes/0,1 ha, com evidências de que a maioria das árvores que ocorrem na área representa, na realidade, rebroto de plantas que já haviam sido cortadas anteriormente (ALVES; SASSI, 2003). No rio Timbó a madeira de mangue é usada na pesca, construção de trapiches, fabricação do carvão, construção de casas e pocilgas e como combustível, o que também acontece em outros estuários da região. No estado do Piauí, por exemplo, seu uso inclui, ainda, a confecção de cercas que isolam porcos que são criados dentro do manguezal (NASCIMENTO, 1999) e na Paraíba a madeira do mangue (especialmente Laguncularia racemosa) é também usada para a fabricação de embarcações e mobiliários domésticos (VIDAL, 2000). No Estado do Paraná (Sul do Brasil) a retirada da madeira é a segunda principal importância do manguezal (ATHAYDE; THOMAZ, 1996).

A supressão da vegetação de mangue para construção de viveiros também ocorre em muitos manguezais do Brasil (BRAGA et al., 1989; VIDAL, 2000). A expansão da carcinicultura tem degradado extensas áreas de mangue em todo o mundo (PÁEZ-OSUNA et al., 1998; BLANCHARD; PRADO, 1995; HUITRIC et al., 2002), o que requer medidas urgentes de controle dessa atividade.

Nossos dados refletem o que vem acontecendo em outros manguezais do mundo, concordando com as observações de Mastaller (1987). A maioria dos impactos evidenciados degrada o ambiente, alterando sua ordem estética, com profundas mudanças nas paisagens locais. Demonstram, também, que existe falta de compromisso do poder público local em tratar as questões ambientais com responsabilidade, refletidas, em especial, na ausência de formas corretas de ordenamento do uso do solo e zoneamento urbano, e na falta de programas de gestão ambiental adequados.

Com exceção, talvez, das comunidades locais de pescadores artesanais, especialmente os que residem na localidade de Cueiras, na margem esquerda do estuário, que seguramente tem consciência dos bens e serviços oferecidos pelo ambiente, uma vez que dependem dele para sua sobrevivência, evidencia-se que, em função das tensões antrópicas que foram observadas, grande parte das populações locais não está compromissada com a manutenção da integridade ecológica da área. Dessa forma, nossos dados também demonstram o quanto a sociedade local se acha alienada para com as questões ambientais, um reflexo claro e evidente da falta de educação no tocante ao uso do espaço e dos serviços que o ambiente lhes oferece.

A perda de qualidade ambiental evidenciada em grande parte dos setores pesquisados pode ser traduzida como diminuição dos recursos e dos serviços que o ecossistema pode oferecer. Tomando-se como base alguns dos principais indicadores dos diferentes tensores observados, como

Tropical Oceanography, Recife, v. 33, n. 2, p. 199-206, 2005. 
esgotos e supressão do manguezal, por exemplo, é possível prever alguns prejuízos resultantes dessas ações. Algumas interferências acarretam não somente a perda de qualidade ambiental e alterações na ordem estética do ambiente, mas podem levar, também, à queda da produtividade pesqueira, a redução de habitats, a perda de biodiversidade e a sérios problemas de saúde pública, com profundas conseqüências econômicas e sociais.

Percebe-se, com este estudo, que grande parte das formas atuais de uso do espaço estuarino do rio Timbó são conflitantes e potencializam impactos secundários cumulativos, gerando drásticas mudanças ambientais com progressivas perdas de qualidade ambiental para as gerações presentes e futuras, evidenciando claramente que a atual forma de manejo da área é insustentável uma vez que carecem dos compromissos éticos de equidade inter e intrageracional conforme previstos nos princípios do desenvolvimento sustentável.

A pesquisa aponta para a necessidade urgente de interferências nesse ambiente, quer no sentido de gerenciamento do espaço ou em ajustes nas leis específicas que beneficiará a conservação dos recursos naturais. Considerando-se que o incremento dos impactos relaciona-se diretamente com o incremento das populações humanas e suas atividades, é fácil prever que o quadro deverá se agravar de forma expressiva numa escala de tempo muito curta. A redução dos recursos pesqueiros do estuário, a intensificação na ocupação nas áreas marginais, as derivações conseqüentes dessa ocupação (poluição e contaminação das águas, diminuição de áreas de mangues, mortandade da fauna, etc.) certamente representam o preço a ser pago se nenhuma ação de curto prazo for estabelecida quanto à necessidade do estabelecimento de um programa integrado de manejo. Educação ambiental e implementação de atividades econômicas não consumíveis como o ecoturismo, por exemplo, acoplado a um programa de gestão integrada e participativa (CLARK, 1997; BARROS et al., 2000; REIS; D’INCAO, 2000), envolvendo tanto o poder político como os usuários do espaço estuarino, são as melhores formas de gestão que poderão garantir a sustentabilidade de uso do ambiente e sua conservação, desde que respeitem aspectos das culturas locais, religiões, diferenças sociais e os diferentes níveis de formação educacional das pessoas que se relacionam direta ou indiretamente com o espaço estuarino.

\section{REFERÊNCIAS BIBLIOGRÁFICAS}

AGENDA 21 - ANEXO: Declaração do Rio de Janeiro sobre meio ambiente e desenvolvimento. Princípio 3. Disponível em, http://www.ecolnews.com.br/agenda21/agenda21-anexo.htm. Acesso em 15 de mai. 2005.

ALVES J. B; SOUTO, J. S.; SILVA, W. A.; LOPES, L. I.; RODRIGUES, C. R.F. Diagnóstico ambiental de ruas e bairros da cidade de Teixeira, PB. R. Árvore, v. 28, n. 5, p. 755-764, 2004.

ALVES, R. R. N.; SASSI, R. Phytosociological Characteristics and Anthropogenic Impacts on The Mangrove of Intermares Coastal Lagoon, Northeastern Brazil. PE. Tropical Oceanography, v. 31, n.2, p. 135-147, 2003.

ATAYDE, S. F.; THOMAZ, L. M. Áreas protegidas e comunidades locais da ilha do Mel - PR, Brasil. Nerítica, v. 9, n. 1 - 2, p. 49-91, 1996.

ASSIES, W. To get out of the mud. Neighborhood associativism in Recife, 1964-1988. Amsterdam: Cedla Latin America studies, 1992. p. 348.

AWOSISKA, L.; MARONE, E. Scientific needs to assess the health of the oceans in coastal areas: a perspective of developing countries. Ocean; Coastal Management, v. 43, p. 781-791, 2000.

Tropical Oceanography, Recife, v. 33, n. 2, p. 199-206, 2005. 
BASTOS, R. B.; FEITOSA, F. A. N; MUNIZ, K. Variabilidade espaço-temporal da biomassa fitoplanctônica e hidrologia no estuário do rio Una (Pernambuco - Brasil). Tropical

Oceanography, v. 33, n. 1, p. 1-18, 2005.

BARROS, H. M, ESKINAZI-LEÇA, E.; PARANAGUÁ, M. N. The disappearing Fish: an understanding of sustainability among estuarine fishermen communities of Bragança, PA. Aquatic Ecosystem Health and Management, v. 3, p. 553-560, 2000.

BLANCHARD, J.; PRADO, G. Natural regeneration of Rhizophora mangle in strip clearcuts in North West Ecuador. Biotropica; v. 27, n. 2, p. 160-167, 1995.

BRAGA, R. A. P.; UCHOA, T. M. M.; DUARTE, M. T. M. B. Impactos ambientais sobre o manguezal de Suape-PE. Acta Bot. Bras., v. 3, n. 2, p. 9- 27, 1989.

BRAGA, E. S.; BONETTI, C. C. V. D.; BURONE, L.; BONETTI FILHO, J. Eutrophication and Bacterial Pollution Caused by Industrial and Domestic Wastes at the Baixada Santista Estuarine System-Brazil. Mar. Poll. Bull., v. 40, n. 2, p. 165-173, 2000.

CAVALCANTI, L. B., MACEDO, S. J.; PASSAVANTE, J. Z. O. Estudo ecológico da região de Itamaracá, Pernambuco - Brasil. XXI. Caracterização do Canal de Santa Cruz em função dos parâmetros físico-químicos e pigmentos fotossintéticos. Trab. Oceanog. Univ. Fed. PE, v. 16, p. 157-216, 1981.

CICIN-SAIN, B,; KNECHT, R.W., Integrated coastal and ocean management: concepts and practices. Island Press, Washington, pp. 517. 1998

CINTRÓN, G.; SCHAEFFER-NOVELLI, Y. The mangrove ecosystem: Research methods. In: SNEDAKER, S. C.; SNEDAKER, J. G. (eds.). Methods for studying mangrove structure. United Kingdom: UNESCO, Bungay, 1984, p. 91-113.

CLARK, J. Coastal zone management for the new century. Ocean and Coastal Manag., v. 37, n. 2, p. 191-216, 1997.

CPRH - Companhia Pernambucana de Controle da Poluição Ambiental e de Administração dos Recursos Hídricos. Monitoramento da qualidade das águas nas Bacias Hidrográficas Litorâneas. Recife, p. 18-77, 1997.

CPHR - Companhia Pernambucana de Controle da Poluição Ambiental e de Administração dos Recursos Hídricos. Monitoramento da qualidade das águas nas Bacias Hidrográficas Litorâneas. Recife, p. 22- 43, 1999.

DAME, R. F.; ALLEN, D. M. Between estuaries and the sea. J. Exp. Mar. Biol. Ecol., v. 200, p. 169-185, 1996.

EKAU, W.; WESTHAUS-EKAU, P.; MACÊDO, S. J.; DORRIEN, C. The Larval Fish Fauna of the Canal de Santa Cruz - Estuary in Northeast Brazil. Tropical Oceanography, v. 29, n. 2, p. 117-128, 2001.

ESKINAZI-LEÇA, E., MACEDO, S. J.; PASSAVANTE, J. Z. O. Estudo ecológico da região de Itamaracá, Pernambuco - Brasil. V. Composição e distribuição do microfitoplâncton do Canal de Santa Cruz. Trab. Oceanog. Univ. Fed. PE, v. 15, p. 185-262, 1980. 
FRENCH, P. Coastal and estuarine management. London, Routledge, 1997, 243 p.

FLINDT, M. R.; PARDAL, M. A.; LILLEBO, A. I.; MARTINS, I.; MARQUES, J. C. Nutrient cycling and plant dynamics in estuaries: A brief review. Acta Oecologica, v. 20, n. 4, p. 237-248, 1999.

FONSÊCA, F. T. B.; PARANAGUÁ, M. N.; AMADO, M. A. M. Copepoda Parasitas de Peixes Mugilidae Cultivados em Itamaracá - Pernambuco - Brasil. Tropical Oceanography, v. 28, n. 2, p. 117-132, 2000.

HAMILTON, G. B.; SNEDAKER, S. C. Handbook for mangrove area management: Environment and Policy. Institute, East-West Centre, Honolulu, Hawaii, USA: Int. Union for the Conservation of Nature and Natural Resources, Switzerland and Unesco, Paris, 123 p. 1984.

HONORATO DA SILVA, M.; PASSAVANTE, J. Z. O.; SILVA-CUNHA, M. G. G.; GREGO, C. K. S.; MUNIZ, K. Distribuição espacial e sazonal da biomassa fitoplanctônica e dos parâmetros hidrológicos no estuário do rio Formoso, (Rio Formoso, Pernambuco, Brasil). Tropical Oceanography, v. 32, n. 1, p. 89-106, 2004.

HUITRIC, M., FOLKE. C.; KAUTSKY, N. Development and government policies of the shrimp farming industry in Thailand in relation to mangrove ecosystems. Ecol. Economics, v. 40, p. 441455, 2002.

KUSUMA-ATMADJA, M.; PURWAKA, T. H. Legal and institutional aspects of coastal zone management in Indonésia. Mar. Policy, v. 20, n. 1, p. 63-86, 1996.

LUGO, A. E., CINTRÓN, G.; GOENAGA, C. El ecosistema del manglar bajo tensión; pp. 261-285. In: Memorias del seminario sobre el estudio científico e impacto humano en el ecosistema de manglares. Montevideo: UNESCO, ROSTLAC, 1980, 405 p.

MARCELINO, R. L. Diagnóstico sócio-ambiental do estuário do rio Paraíba do Norte - PB, com ênfase nos conflitos de uso e interferências humanas em sua área de influência direta. João Pessoa, 2000. 99f. Dissertação (Mestrado em Meio Ambiente) - Programa de Pós-Graduação em Desenvolvimento e Meio Ambiente. Universidade Federal da Paraíba.

MASTALLER, M. Resumo da literatura sobre o conceito do uso de áreas de mangue com referência especial para a agricultura artesanal. IBAMA, 1987. 79 p.

MELLO, R. L. S. Fauna malacológica do mesolitotal da Ilha de Itamaracá - Pernambuco. Anais da Universidade Federal Rural de Pernambuco, v. 4, p. 157-166, 1979.

MOURA, A. S. Terra do mangue: invasões urbanas no Recife. Recife, Fundação Joaquim Nabuco/Massangana. 1990.

MOURA, N. F. O.; COELHO, P. A. Fecundidade de Goniopsis cruentata (Latreille, 1803) (Crustacea, Brachyura, Grapsidae) no manguezal do rio Paripe - Pernambuco - Brasil. Tropical Oceanography, v. 31, n. 2, p. 127-133, 2003.

NASCIMENTO, M. S. V. O Manguezal dos rios Tinhonha- Ubatuba, Ceará - Piauí, Brasil: Composição, estrutura e diagnóstico sócio-ambiental. João Pessoa, 1999. 136 f. Dissertação

Tropical Oceanography, Recife, v. 33, n. 2, p. 199-206, 2005. 
(Mestrado em Meio Ambiente) - Programa de Pós-Graduação em Desenvolvimento e Meio Ambiente. Universidade Federal da Paraíba

PÁEZ-OSUNA, F.; GUERRERO-GALVÁN, S. R.; RUIZ-FERNÁNDEZ, A. C. The Environmental Impact of Shrimp Aquaculture and the Coastal Pollution in México. Mar. Poll. Bull., v. 36, n. 1, p.65-75, 1998.

PARANAGUÁ, M. N.; NEUMANN-LEITÃO, S. Estudo ecológico da região de Itamaracá, Pernambuco - Zooplâncton dos viveiros de cultivo de peixes de Itamaracá, PE. Rev. Nordestina Biol., v. 3 (especial), p. 187-206, 1980.

PASSAVANTE, J.Z.O. Produção primária do fitoplâncton do Canal de Santa Cruz (Itamaracá - PE). São Paulo, 1979. 188f. Tese (Doutorado em Oceanografia) - Instituto Oceanográfico da Universidade de São Paulo - IOUSP. Universidade de São Paulo.

PREMANATHAN, M.; ARAKAKI, R.; IZUMI H.; KATHIRESAN, K.; NAKANO, M.; YAMAMOTO, N.; NAKASHIMA, H. Antiviral properties of a mangrove plant, Rhizophora apiculata Blume, against human immunodeficiency virus. Antiviral Research, v. 44, p. 113-122, 1999.

REIS, E.G.; D'INCAO, F. The present status of artisan fisheries of extreme Southern Brazil: an effort towards community-based management. Ocean and Coastal Management, v. 43, p. 585595, 2000.

ROHDE, G. M. Estudos de impactos Ambiental. Porto Alegre: CIENTEC Boletim Técnico n. 4, 1988, 42p.

SASSI, R; MARCELINO, R. L.; COSTA, C. F. Contrastes sociais e usos conflitivos em uma área estuarina do Nordeste do Brasil. In:Congresso Latino Americano de Ciências do Mar, 11, Resumos Viña Del Mar, v. 1. p. 24, 2005.

SCHWAMBORN, R.; NEUMANN-LEITÃO, S.; SILVA, T. A.; SILVA, A. P.; EKAU, W.; SAINT-PAUL, U. Distribution and Dispersal of Decapod Crustacean Larvae and Other Zooplankton In The Itamaracá Estuarine System, Brazil. Tropical Oceanography, v. 29, n. 1, p. 118, 2001.

SILVA, A. J. Estudo Sócioambiental na Margem Urbana do Canal de Santa Cruz, Itapissuma - Pernambuco-Brasil. Recife, 2001. 194f. Dissertação (Mestrado em Meio Ambiente) - Programa Regional de Pós-Graduação em Desenvolvimento e Meio Ambiente. Universidade Federal da Paraíba.

SILVA, J. D. V. Composição Florística e Estrutura da vegetação do manguezal de Vila Velha, Ilha de Itamaracá-PE. Recife, 1990. 100f. Monografia (Graduação em Ciências Biológicas) Universidade Federal Rural de Pernambuco.

SILVA, J.D.V. Parâmetros Oceanográficos e distribuição das espécies e bosques de mangues do estuário do rio Paripe-PE. Recife, 1995. 107f. Dissertação (Mestrado) - Universidade Federal Rural de Pernambuco.

SÔNIA-DA-SILVA, G.; MELLO, R. L. S.; NASCIMENTO, A. E.; MESSIAS, A. S.; ARAÚJO, S. F. S. A sustentabilidade ecológica das atividades pesqueiras artesanais e a relação com a

Tropical Oceanography, Recife, v. 33, n. 2, p. 199-206, 2005. 
malacofauna no manguezal do Rio Formoso, Pernambuco, Brasil. Tropical Oceanography, v. 28, n. 2, p.155 - 169, 2000.

SOUZA, F. A. M. Land Tenure Security and Housing Improvements in Recife, Brazil. Habitat Intl., v. 23, n. 1, p.19-33, 1999.

SOUZA, M. R. M.; NEUMANN-LEITÃO, S. Conseqüências sócio-econômicas dos impactos antrópicos no rio São Francisco em Brejo Grande, Sergipe - Brasil. Tropical Oceanography, v. 28, n. 1, p. 97-116, 2000.

TOMMASI, L. R. Estudo de impacto ambiental. São Paulo: CETESB, Terragraph Artes e Informática, 1994. 354 p.

VALIELA, I.; BOWEN, J. L. Nitrogen sources to watersheds and estuaries: role of land cover mosaics and losses within watersheds. Environ. Poll., v. 118, p.239-248, 2002.

VASCONCELOS FILHO, A. L.; RAMOS-PORTO, M. Informações preliminares sobre o meio bentos da região estuarina de Vila Velha, Itamaracá - Pernambuco. Anais da Sociedade Nordestina de Zoologia, v. 2, n. 2, p. 133-166, 1987.

VIDAL, W. C. L.; SASSI, R. Influência do manguezal na região marinha adjacente. In: Silva, M. J. L (org.). Iniciados. 4 a ed., João Pessoa: Gráfica e Editora Santa Clara, 1998. p. 89-107. 